\title{
Using Concept Maps to Teach Dyslexic Students Science: The Educators' Approach
}

\author{
Athanasios Vlachos \\ ORCID: 0000-0003-2390-796X • ResearcherID: V-8352-2017 \\ Milen Zamfirov \\ ORCID: 00oo-0003-2231-015X • ResearcherID: V-8511-2017 \\ Sofia University "St. Kliment Ohridski" \\ Faculty of Preschool and Primary School Education
}

Received 10 November 2017 • Revised 17 December 2017 • Accepted 20 December 2017

\section{Abstract}

In this paper educators provide a valuable feedback in the use of concept maps in secondary education. More specifically their use in teaching dyslexic students Science. Almost 100 educators replied to an online questionnaire after they studied a set of evaluation sheets provided to them based on concept maps. We will begin with a brief presentation of the specific learning difficulty of dyslexia; following that are the main general characteristics and challenges that dyslexic students face. Also, the organization of Science classes for the dyslexic student is briefly discussed. Then information regarding concept maps is given. A presentation and quick discussion of four evaluation sheets with concept maps in the science subjects of Chemistry, Biology and Physics is performed. The main part of this paper presents the questionnaire along with a discussion regarding its results. Finally, conclusion are drawn and future work is mentioned.

Keywords: dyslexia, science classes, concept maps, questionnaire.

\section{Introduction}

The definition of the dyslexia given by the International Dyslexia Association is the following (Definition ..., 2017):

"Dyslexia is a specific learning disability that is neurobiological in origin. It is characterized by difficulties with accurate and/or fluent word recognition and by poor spelling and decoding abilities. These difficulties typically result from a deficit in the phonological component of language that is often unexpected in relation to other cognitive abilities and the provision of effective classroom instruction. Secondary consequences may include problems in reading comprehension and reduced reading experience that can impede growth of vocabulary and background knowledge".

Dyslexia is studied from different perspectives and different Sciences. Scientists from the areas of medicine, psychology and education have studied it producing theories that do not overlap in the majority of them.

(C) Authors. Terms and conditions of Creative Commons Attribution 4.0 International (CC BY 4.0) apply. Correspondence: Athanasios Vlachos, Kallithea Kanalia, 49100, Kerkyra, Greece, E-mail: 
- Participants are well aware of the challenges that apply to teaching dyslexic students.

- Most of the participants use quite often evaluation sheets and have a quite good knowledge of concept maps.

- Most of the participants answered that concept maps can be helpful in revision of a science class.

- Participants thought that concept maps improve memory, metacognitive skills of dyslexic students.

- Participants thought that concept maps facilitate learning of procedures from dyslexic students.

In the following sections of this paper the general characteristics and challenges that dyslexic students face are presented, followed by the organization of Science classes for the dyslexic student and a reference to concept maps. Then four evaluation sheets based on concept maps in science classes are briefly presented. The main part of this paper focuses on the questionnaire which was given to approximately 100 educators and its results. Finally, there exists a discussion of the results along with our conclusions.

\subsection{General characteristics and challenges that dyslexic students face}

When demanding subjects like Science are being taught to students with specific learning difficulties, or more specifically dyslexia, educators must cope with an even more challenging situation.

Specifically, students with Specific Learning Difficulties (SLD) although they are quite bright (they rank in IQ tests above average) they have severe difficulties in reading, writing and spelling. They perform better in oral than written examinations, and may show signs of attention deficit hyperactivity disorder (ADHD). In mathematics, they face difficulties in calculations and often perform computations with their fingers. They find it difficult to learn sequential processes, forget symbols (+ or -) and make basic computations by heart.

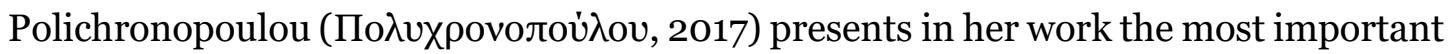
signs of dyslexia in the Greek language according to observations from Greek educators:

- Inversion of letters - numbers (3 for $\varepsilon$ );

- Mirror reading or writing ( $\mu \varepsilon$ for $\varepsilon \mu$ );

- Replacement of words with others that have similar meaning;

- Changing, missing or adding letters in the same word;

- Unjustified and weird mistakes, illegible writing;

- Difficulty in copying from the board;

- Difficulty in memorizing forms, tables, dates and names in order;

- Difficulties in the orientation of time and place.

\subsection{Organization of Science classes for the dyslexic student}

Some characteristics of the Science classes' organization for the dyslexic student appear, such as the following:

- Science subjects should be organized and adapted in a multisensory way, both the theory as well as the related problems;

- The goals of the subject should be stated;

- The required information must be presented in an organized manner;

- Theory could be taught through a fictional story, or a fairytale;

- Main points should be stressed out;

- Easy to grasp examples should be utilized; 
- Information should be presented with more than one ways;

- Visual - spatial representations used when needed;

- $3 \mathrm{D}$ models wherever applicable should be presented;

- Simple exhibition experiments, with easy - to - find everyday life materials, should be carried out;

- Use of simulation software for certain experiments; and

- The main points of each lecture should be repeated in the end.

Zamfirov (2011) also presents an interesting approach towards teaching Science to students with special needs. He states that:

"A bigger part of the physical objects - such as: atom, atomic nucleus, electron, proton, neutron, stars, galaxies, nebulas, etc. cannot be observed directly not only in the nature but even when special equipment and laboratory conditions are provided. The overcoming of those obstacles is possible only in case that accessible and interesting performance of the teaching contents including many visual stimulus - schemes, diagrams, pictures, photographs and primarily models of objects and processes - computer programs that visualize different processes. All that is connected with development of students' abstract thinking and finding ways to extract information from that visual stimulus".

\subsection{Concept maps}

Concept maps are graphical tools for organizing and representing knowledge. They include concepts, usually enclosed in circles or boxes of some type, and relationships between concepts indicated by a connecting line linking two concepts. Words on the line, referred to as linking words or linking phrases, specify the relationship between the two concepts. We define concept as a perceived regularity or pattern in events or objects, or records of events or objects, designated by a label. The label for most concepts is a word, although sometimes we use symbols such as + or \%, and sometimes more than one word is used.

Concept maps were developed in 1972 in the course of Novak's research program at Cornell University where he sought to follow and understand changes in children's knowledge of science (Canas \& Novak, 2017). They were mainly based on Ausubel's work in the concept of meaningful learning, where the new knowledge to acquire is related to previous knowledge. So basically, learners are "integrating" new information to old information.

The basic categories of concept maps are hierarchy concept maps, spider concept maps, flowchart concept maps and system concept maps. They have been used in different educational fields; namely in Science, History, Language and Informatics.

Dyslexic students can benefit by using multisensory teaching methods which include concept maps in Science classes. Scientific terms and mathematical equations can be presented more clearly and efficiently with them (Pavey, Meehan \& Davis, 2013). These students read quite slowly, get easily tired and discouraged. They also face difficulties in understanding information in writing, which causes quite a few difficulties for home study. But with the use of concept maps as revising tools they can greatly improve their school performance (Lami, 2008).

process:

Below are some of the possible applications of concept maps in the educational

- Students making their own concept map;

- Corrections in a given concept map by doing the necessary adjustments in the concepts used and/or the relations between them;

- Adding new concepts in an already structured concept map; 
- The completion of an unfinished concept map with concepts, relations among them, linking words or phrases between concepts;

- Any combination of the above.

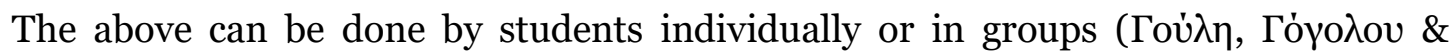

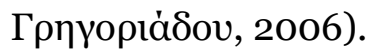

\section{Concept maps used for teaching dyslexic students Science}

In our research for innovative methods of teaching students with dyslexia Science we believe that our approach should include multi-sensory instructional methods. A lecture of Science adapted for dyslexic students should include the use of the student's senses, examples from everyday life, concept maps, graphs, tables. They would bring a holistic approach to learning and attract student's attention.

An early work by (Ferentinou, Papalexopoulos \& Vavougios, 2009), which presented force F in High School physics by using concept maps gave us strong motivation to study and apply further concept maps. In this part four evaluation sheets concerning the science subjects of Chemistry, Biology and Physics are presented and briefly discussed. They are given to students for 10 to 15 minutes. Students are divided in two groups, ideally of the same number where dyslexic students are in both groups. From their answers to the questions of each evaluation sheet an assessment of can be performed. The complete evaluation sheets are presented in the end of this paper.

\subsection{Teaching dyslexic students Chemistry using concept maps}

We concluded in the use of the physical states of matter in the subject of Chemistry, which is taught in the second grade of High School in the Greek educational system (Vlachos \& Zamfirov, 2017). It should be noted that it is the first year that students are taught Chemistry. Two concept maps will be utilized; one with the physical states of matter and their characteristics regarding mass, volume and shape (Figure 1). The other (Figure 2) presents the three states of matter that the school book presents (there exists one more which is omitted; plasma state) and the transitions between them.

Students will be split in two groups; the one group will be taught with the conventional way and the other one through concept maps. Following that they will both answer a set of questions. The set of questions is presented later in this paper. All this procedure should be completed within 45 minutes.

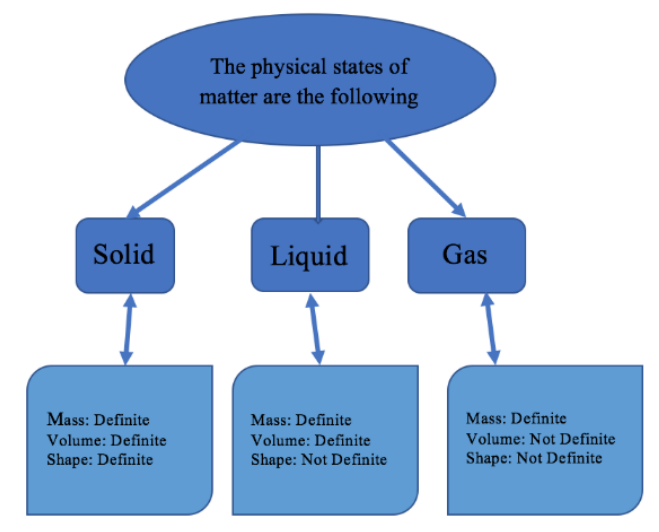

Figure 1. Concept map of physical states of matter 


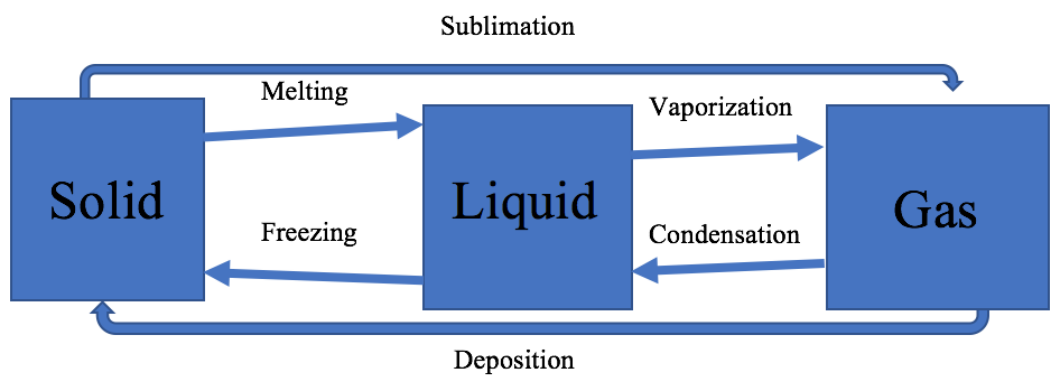

Figure 2. Concept map of transition of physical states

Questions:

1. Match the change of state with the name of the procedure:

\begin{tabular}{|l|l|}
\hline \multicolumn{1}{|c|}{ Change of state } & \multicolumn{1}{|c|}{ Procedures } \\
\hline a. From Solid to Liquid & 1. Freezing \\
\hline b. From Solid to Gas & 2. Deposition \\
\hline c. From Liquid to Gas & 3. Condensation \\
\hline d. From Gas to Liquid & 4. Melting \\
\hline e. From Liquid to Solid & 5. Sublimation \\
\hline f. From Gas to Solid & 6. Vaporization \\
\hline
\end{tabular}

2. Fill in the gaps in the following phrases with words (definite, not definite):

a. Solids have volume and shape.

b. Liquids have

c. Gases have volume and shape.

Following the answer of the above questions from the students we will be able to study if our method provided any improvement in the understanding of the students and to what degree.

\subsection{Teaching dyslexic students Biology using concept maps}

In the science subject of Biology, we use concept maps in the human respiratory system which is taught in the $1^{\text {st }}$ grade of high school (B $\lambda$ áxos \& Zamfirov, 2017). This is a quite complex and demanding class module and poses many difficulties even to the general student population. We split the students in two groups; the first in the end creates the concept map of the human respiratory system, while the second one will just perform a recapitulation of the module. Then an evaluation sheet is given to both teams.

The students have to create the concept map presented in figure 3. In order to create it we provide them with a small guidance - help. Depending on their level as well as their skills, the number and the names of the organs are provided. Or just their number.

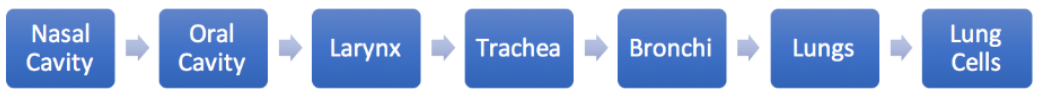

Figure 3. Concept map of the human respiratory system of organs

By using concept maps in the end of a module we help dyslexic students in its review. In this specific module, we provide them with help and guidance to learn a difficult sequence, like the human respiratory system. It contains a large number of organs and quite difficult scientific terminology. 
A concept map of the organs of the human respiratory system in which the students can add notes is presented in Figure 4. This concept map can help students in the revision of a module, but it can also be used for evaluation purposes.

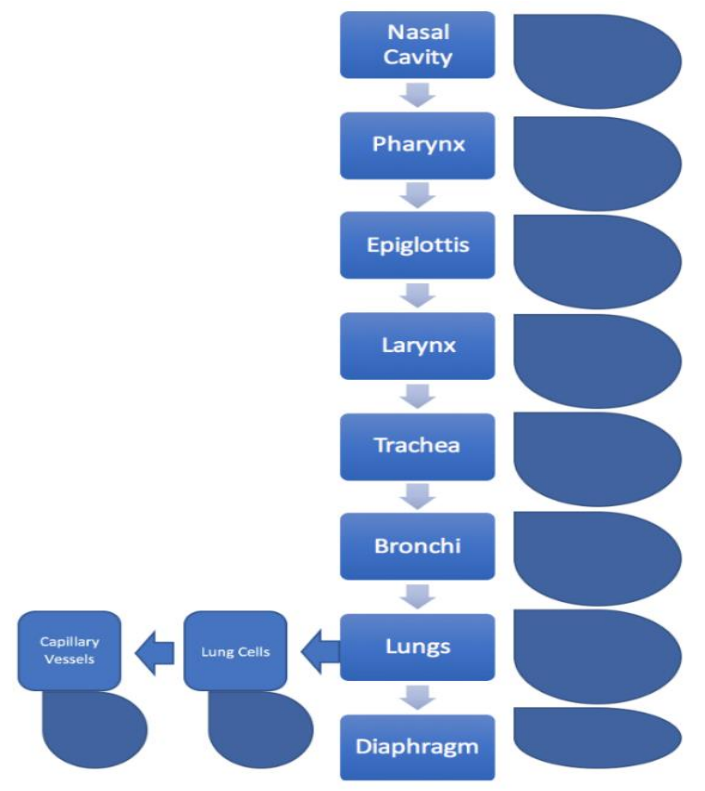

Figure 4. Concept map of the organs of the human respiratory system in which the students can add notes

\subsection{Presentation of mathematical equations of Physics} using concept maps (Ohm's Law, density)

In the science subject of Physics, we utilized concept maps for Ohm's law and the mathematical equation of density d (Bגáxos \& Zamfirov, 2017). These two impose increased difficulties to all students; especially to dyslexic students. Ohm's law is very important since it is used not only in class exercises, but also in lab exercises during the $3^{\text {rd }}$ grade of high school. On the other hand, the mathematical equation of density is used in lab exercises in the $1^{\text {st }}$ grade of high school and in class exercises in the $2^{\text {nd }}$ grade.

It should be noted that a discussion is being made with the students during a brief theoretical presentation about the role that material of the resistor plays in the calculation of the resistance (Ohm's law). Apart from stating that electrical resistance is different in every material; also, temperature and dimensions of the resistor (length, cross section area) also affect its resistance. Likewise, in the theoretical discussion concerning density, a presentation of the equation that calculates the density of a material $(\mathrm{d}=\mathrm{m} / \mathrm{V}$, where $\mathrm{m}$ the mass and $\mathrm{V}$ the volume) is made. Subsequently, through examples and discussion it is presented that density is different in every material.

The computation of $\mathrm{X}$ of a mathematical equation $\left(\mathrm{A}^{*} \mathrm{X}=\mathrm{B}\right)$ is taught in $2^{\text {nd }}$ grade mathematics class and presents increased difficulty to all student population. Ohm's law and density are computed with equations $\left(\mathrm{A}^{*} \mathrm{X}=\mathrm{B}\right)$. Science class teachers often have to present or to remind mathematical knowledge that is vital to their subject. Unfortunately, the curriculum of mathematics and science do not go hand in hand. So quite often students have to be reminded or even taught of necessary mathematical knowledge in science subjects.

With the concept maps presented in figures 5 and 6 below, the mathematical equations of Ohm's law and density d are solved for each variable. So, depending on the data the appropriate equation form is used. After a brief theoretical presentation of Ohm's law, the concept map is 
presented. Then examples are taught where I (current intensity), V (voltage) and R (resistance) are computed.

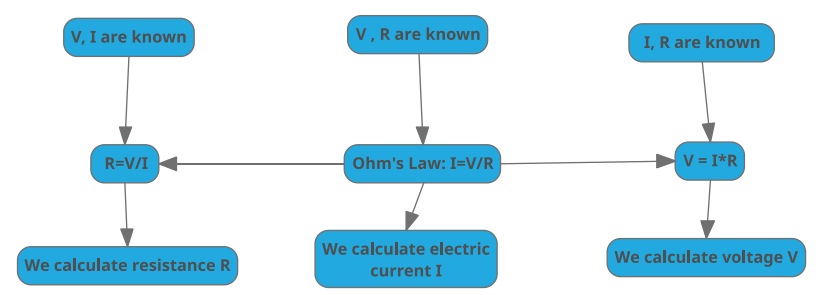

Figure 5. Concept map of Ohm's law

A similar procedure is being followed in the case of density (theory, concept map, examples, exercises to solve) where the mathematical equation of density is solved for the variables: $\mathrm{d}$ - density, $\mathrm{m}$ - mass and V - volume. Each of the concept map can also be used for revision purposes from students.

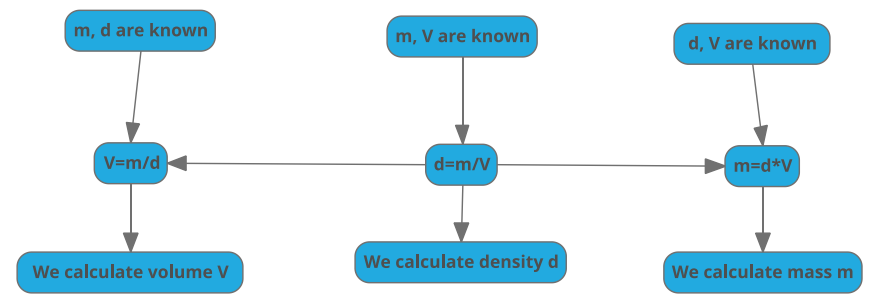

Figure 6. Concept map of the mathematical equation of density $\mathrm{d}$

\section{Questionnaire}

We provided an electronic questionnaire to colleagues asking their opinion on concept maps in general and more specifically on the above presented ones. The questionnaire is presented in the end of this paper. It consists of 24 questions, which are all required to be answered in order for it to be submitted. Almost 100, 97 educators to be exact, participated in this research. The majority of the participants are working in Greek public schools in the secondary education. They are either substitute professors or permanent personnel and most of them are working in special education. Below are 24 diagrams, that present the results of our survey.

The questionnaire can be considered of containing three main parts. The first, where some general information about the educators are provided. The second, in which some general information regarding dyslexic students are obtained. And the third, which is the main part that asks for the educators' opinion about concept maps and our evaluation sheets.

\section{Results and Discussion}

As it can be seen in figure 7 , the majority of the educators (58\%) that participated in the survey are women. It is widely known that women dominate public education, both primary and secondary education. In figure 8 , which presents the age of the participants, most of them are aged between 35 and $44(46 \%)$. While more than $3 / 4(76 \%)$ are 25 to 44 years old. This is a contradiction to the fact that teaching staff is aging fast in Greece; with the average age of professors in secondary education being 48 years old. This is partly answered later in question 5 , but it should be noted that special education in Greece is manned mostly with substitute professors. They have an average age of 38 in Greece based on data from the Ministry of Education. So, in fact our data are very well aligned with the official ministry data. 
In the next question, the results of which are presented in figure 9, the highest degree is required to be stated. The seminar in special education can be given, if the recipient has a postgraduate degree. Almost half (47\%) of the participants to this survey hold a Master's degree in Special Education or School Psychology, while 42\% have university postgraduate degree or a seminar in special education. Half of them are highly qualified academically, but on the other hand many do not have any qualifications or hold only a seminar. This is due to the fact that many permanent educators work in special education without any qualifications. Also, some substitute personnel get hired only because of their extended work experience. The law gives the right to substitute professors to work in special education if their work experience is more than 10 months, without any academic qualification. PhD graduates exist in this research, but none of them holds a PhD in Special Education or School Psychology.

Regarding the school that they are currently working, question 4, as it can be seen in figure 10 more than half (57\%) are working in general education which is mainly inclusion classes. Close to one in four are working in a special education school. In general, special schools in Greece are a minority. The high percentage is justified because participants are mainly working in special education. Next in figure 11, years of service of educators (question 5) proves the above mentioned. In Greece, it is almost a decade since the last educators become permanent public servants. Over $60 \%$ have a working experience of less than 10 years. This proves the fact that the majority are substitute teachers. This can also explain the low age average of the participants in question 2. Only $6 \%$ have more than 20 years of work experience.

The educators that answered the questionnaire are most of them women, aged around 35 years old. They hold a Master's degree related to special education, work in Greek public general secondary education and have a working experience of less than 10 years. So, they are quite young of age, with high education. All the above mean that they can most certainly provide adequate schooling to children with special educational needs.

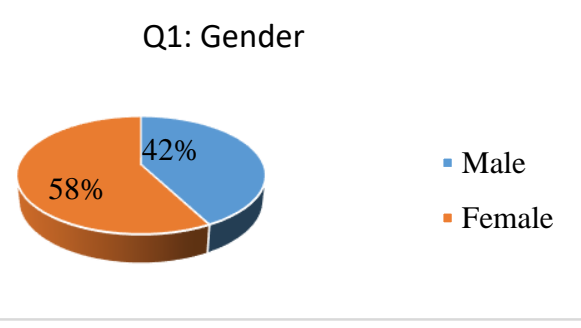

Figure 7. Gender of the participants

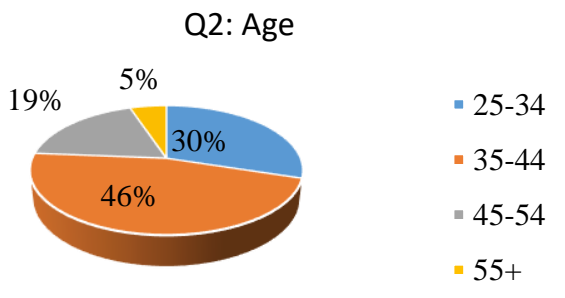

Figure 8. Age of the participants 


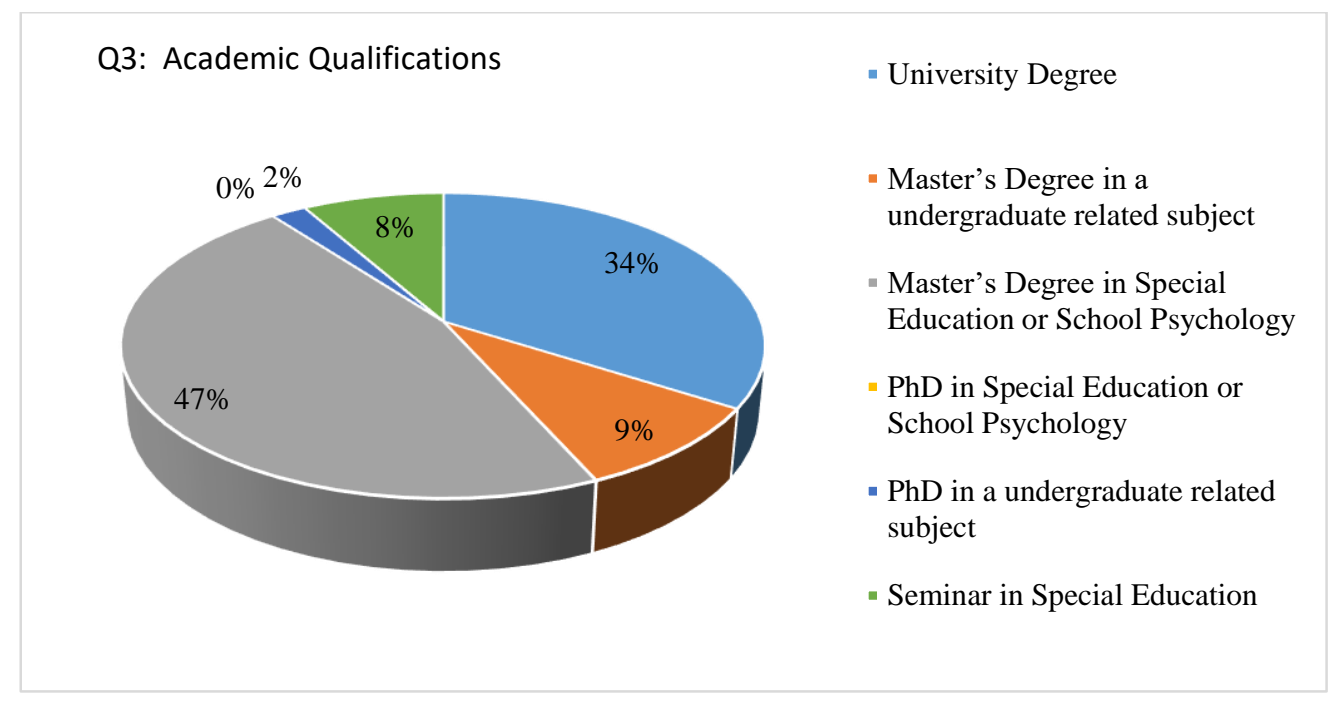

Figure 9. Academic qualification of the participants

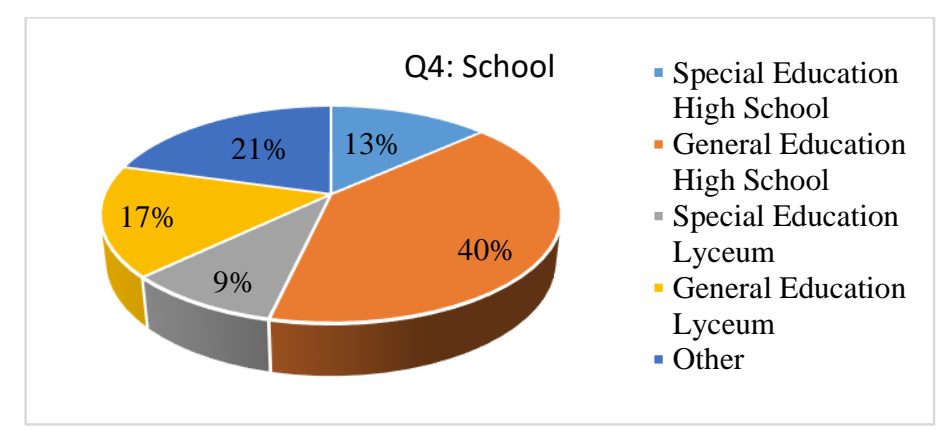

Figure 10. School that the participants are currently working

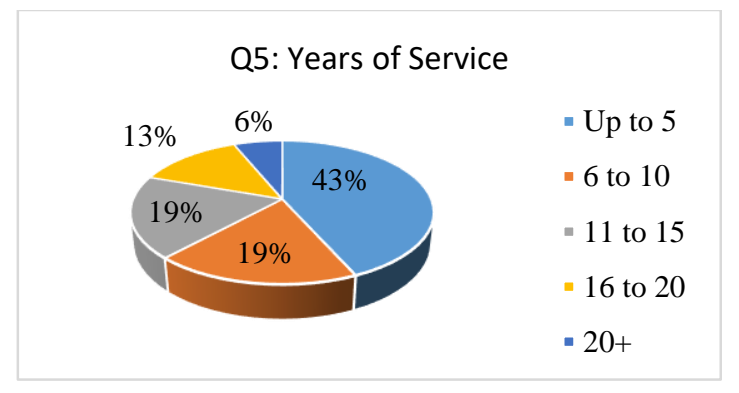

Figure 11. Years of service of the participants

Moving on to the second part of the questionnaire, questions 6 to 9 (Figures 12-15), where general knowledge of dyslexia and of dyslexic students is studied. Since the participants are employed in special education, it is no surprise that all, except one, are familiar with teaching dyslexic students. It can be assumed that the characteristics of dyslexic students are well aware by the educators. That is why, in question 7, no one from the educators answered that they face no difficulties when teaching dyslexic students. This category of student poses quite a few challenges in the teaching process. More specifically, 8 out of 10 stated that they face at least quite a few difficulties. Question 7 is also the first in a total of five questions in the questionnaire, where answers can be given in a scale from 1 to 4 . In question 8 , none of the educators in question provided a negative answer to the need for alteration of the instructions given to dyslexic students. Almost 6 out of 10 where certain that they should be modified, while the rest thought it was quite probable. In question 9, it is very comforting to see that 2 out of 3 educators when questioned 
A. Vlachos \& M. Zamfirov - Using Concept Maps to Teach Dyslexic Students Science: ...

about the collaboration of school and the families of dyslexic students where quite satisfied. Only $3 \%$ was not happy with the school - family relationship.

Again, in questions 6 to 9 it is obvious that the participants are highly skilled and well aware of the characteristics and challenges that dyslexic students apply. It is more than obvious that in order to overcome the increased difficulties; a different approach of teaching should be implemented.

Q6: Have you ever taught dyslexic students?

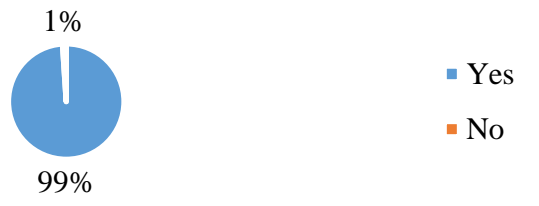

Figure 12. Collaboration with dyslexic students of the participants

Q7: Are there any extra difficulties with the educational process of dyslexic students that you experience?

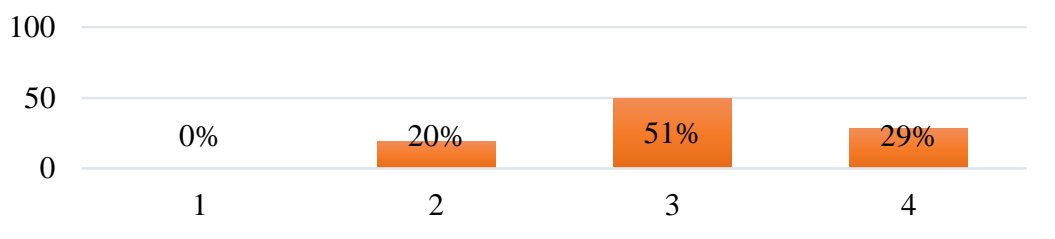

Figure 13. Difficulties faced by the participants with dyslexic students

Q8: Instructions given during the class should be modified in the presence of dyslexic students?

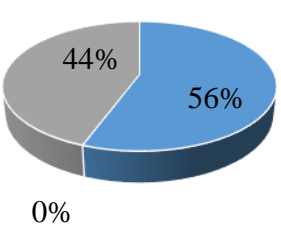

- Yes
- No
- Maybe, on some
ocasions

Figure 14. The opinion of the participants for the instructions given in class

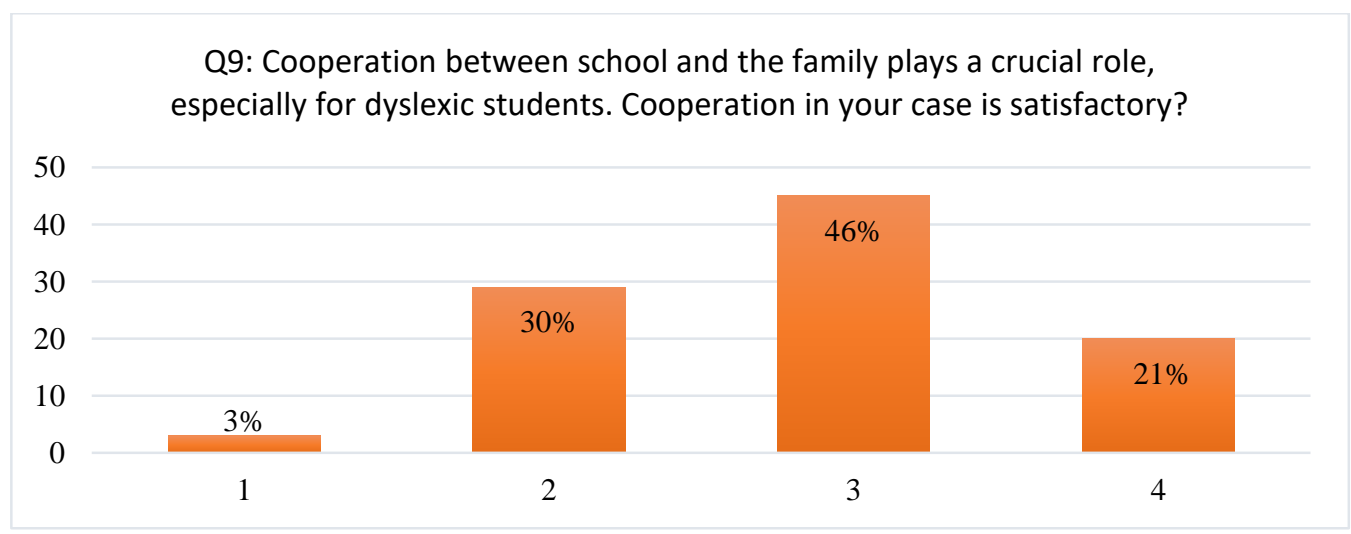

Figure 15. Cooperation of the participants with the families of dyslexic students 
The last part of the questionnaire, figures 16 - 30, focuses on concept maps and their application in the four evaluation sheets provided to the participants. A brief discussion of the evaluation sheets was performed in the previous part of the paper; they can also be accessed in the end of the paper along with the questionnaire. In question 10 participants are asked if they use evaluation sheets in their classes. More than half (60\%) replied that they use them quite often; while only 8 answered that they use them rarely. In the next question, question 11, almost 6 out of 10 stated that they know concept maps. Whereas, only 4 replied that they have no knowledge of them whatsoever. Also, the remaining 38\% answered that they have some basic knowledge of them. Therefore, at least 60\% use quite often evaluation sheets and have a quite good knowledge of what a concept map stands for. In question 12, they were asked to comment on the clarity of the evaluation sheets. Almost 6 out of 10 believe they are very easy to understand, while $89 \%$ believe that they are at least quite easy to understand. The above is very encouraging, especially when it comes from such a knowledgeable group of colleagues. Following that, in question 13, the participants give their feedback in the use of evaluation sheets of this kind and them improving understanding of science related classes. More than 6 out of 10 educators think that they are very helpful. On the other hand, none thought of it as not helping at all and only $7 \%$ consider it slightly helpful. The majority, 93\%, consider them at least quite helpful.

Next two questions, namely 14 and 15 , refer to revision and evaluation sheets of the proposed type as well as concept maps in general. In question 14, revision through evaluation sheets, only one participant gave a negative answer. While more than 3 out of 4 (78\%), believe that evaluation sheets can be helpful as revision material. Revision of a class using concept maps is considered in question 15 . Only 2 gave a negative answer, while an overwhelming $80 \%$ provided a positive answer. In both questions, almost $80 \%$ of the participants answered that concept maps or evaluation sheets based on them can be quite helpful in recapitulation and revision of a science related topic. Moreover, in question 16, 84\% of the participants think that teaching using concept maps is more pleasant than any other conventional method of teaching.

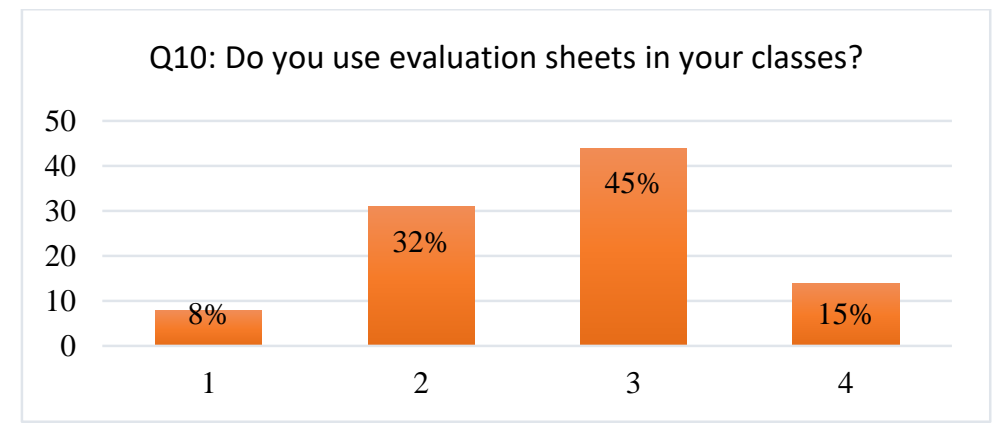

Figure 16. Use of evaluation sheets by the participants

Q11: Are you familiar with concept maps and their use in teaching?

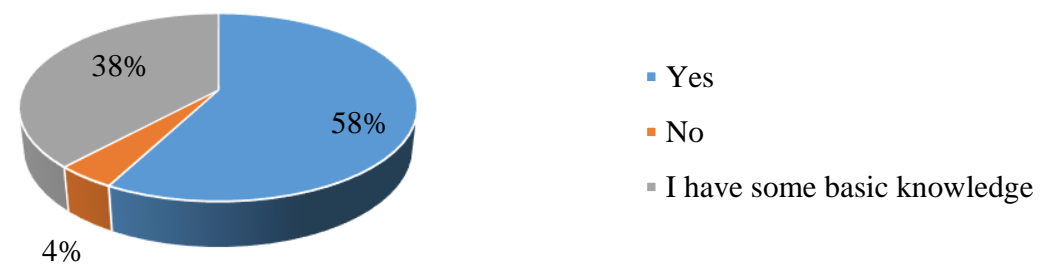

Figure 17. Knowledge of concept maps from the participants 
A. Vlachos \& M. Zamfirov - Using Concept Maps to Teach Dyslexic Students Science: ...

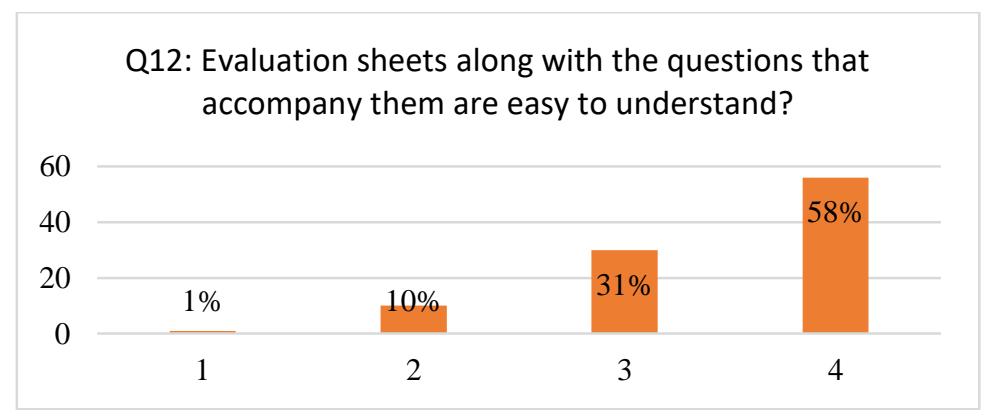

Figure 18. The participants' opinion about the evaluation sheets given to them

Q13: Evaluation sheets can provide valuable help in understanding a science topic?

100

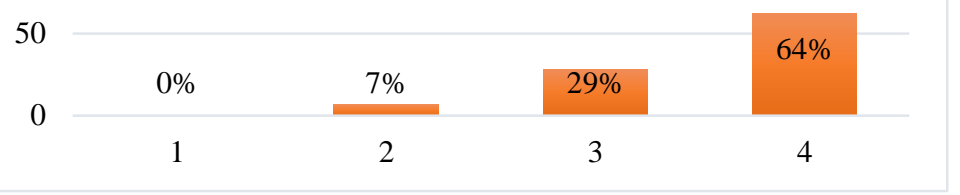

Figure 19. Participants reply on whether evaluation sheets improve understanding of science topics

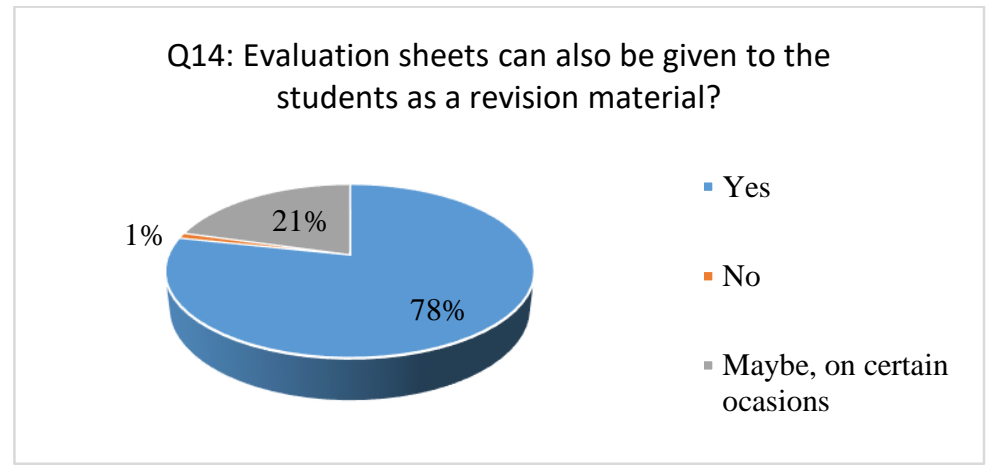

Figure 20. Participants reply on whether evaluation sheets can be given to students for revision

Q15: Revision of a lesson can be achieved with concept maps?

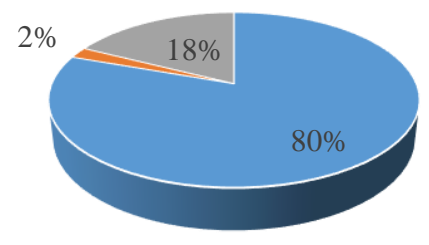

- Yes

- No

- Maybe

Figure 21. Participants reply if concept maps can be used for revision purposes 
Q16: Do you believe that teaching through concept maps is more pleasant in comparison with other teaching methods?

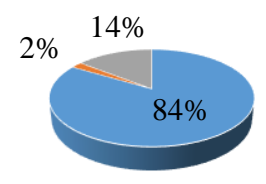

$$
\begin{aligned}
& \text { - Yes } \\
& \text { - No } \\
& \text { - I cannot answer }
\end{aligned}
$$

Figure 22. Comparison of teaching with concept maps to traditional methods

The following 6 questions (figures 23 - 28) are directly related to dyslexic students. In question $17,85 \%$ of the participants to the survey gave a positive answer to whether evaluation sheets of this type can improve the understanding of dyslexic students on science topics. In the next one, which is question 18, evaluation sheets like the ones given to the participants are considered as a medium to improve memorization of mathematical equations and scientific terms for dyslexic students by almost 3 out of 4 of the participants. Likewise, in question 19 a vast percentage of $73 \%$ believes that using similar evaluation sheets can be a great help to dyslexic students at their home study. This can result in reducing reading to a minimum. Also, the great majority (70\%) of educators which were asked agreed with the statement of question 20. They believe that procedures that are complex and include quite a few steps, like mathematical equations, can be learned more easily if they are presented - taught with concept maps. They also agree, partly or fully, with the statement of question 21. Metacognitive skills are thought to be developed by using concept maps by $80 \%$ of the participants. In question 22, only two educators thought that concept maps do not act as a technique that facilitates learning. While, $76 \%$ believed that it can enhance memory of dyslexic students. In the questions referring to dyslexic students specifically, participants thought that concept maps improve memory, metacognitive skills and facilitate learning of difficult and complex procedures.

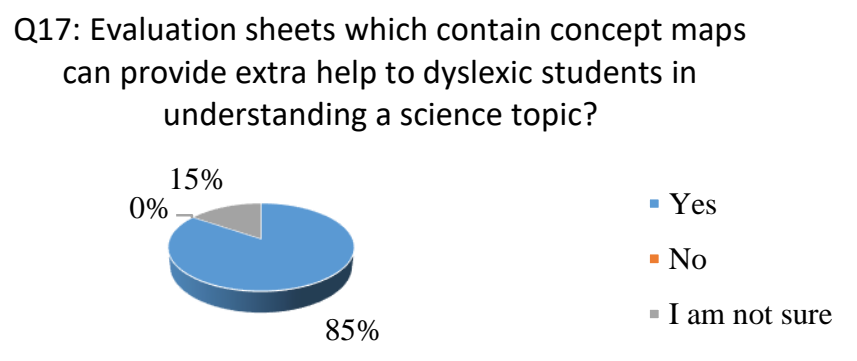

Figure 23. Participants reply on whether evaluation sheets of the type given can help dyslexic students to understand a science topic

Q18: Dyslexic students have difficulties in learning -

memorizing scientific terms and mathematical

equations. Evaluation sheets can help them in order

to gain that kind of knowledge?

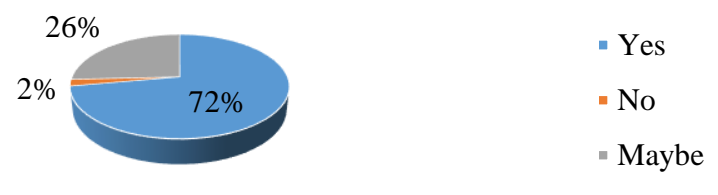

Figure 24. Participants reply to whether the given evaluation sheets can help dyslexic students in learning - memorizing scientific terms 
A. Vlachos \& M. Zamfirov - Using Concept Maps to Teach Dyslexic Students Science: ...

Q19: Dyslexic students usually have difficulties in reading; this makes their studying at home almost impossible. Do you believe that these evaluation sheets which contain concept maps can help them in overcoming these difficulties?

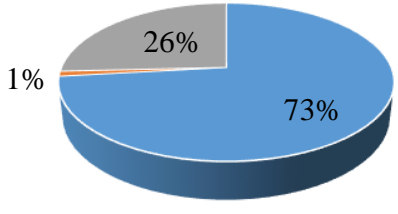

$=$ No

- Maybe

Figure 25. Participants reply on whether concept maps can improve home study

Q20: Dyslexic students usually have difficulties to

learn and to follow complex procedures, like mathematical equations. Do you believe that these can be more easily learned with the use of concept maps?

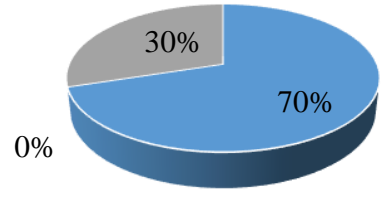

- Yes

$=$ No

- Maybe

Figure 26. Participants reply to whether concepts maps can facilitate learning of complex procedures

Q21: Dyslexic students often need to develop more their metacognitive skills, such as recapitulation, compared to general student population. Do you believe that concept maps help in the development of metacognitive skills?

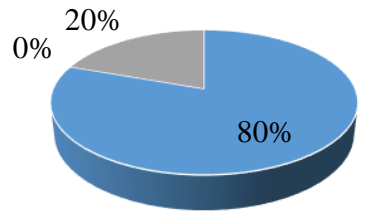

Figure 27. Participants reply to the possible improvement of metacognitive skills by using concept maps 
Q22: Concept maps can be used as a type of memory aid, techniques that facilitate learning?

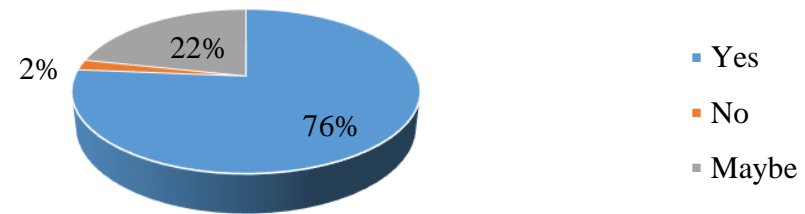

Figure 28. Participants reply on whether concept maps can be used as a type of memory aid

In question 23 (figure 29) the participants were asked to choose one or more group of students which in their opinion would gain the most by using concept maps. The top choices were general student population and students with dyslexia with a percentage of $79 \%$ and $76 \%$ respectively. Next are students with mild retardation (42\%), followed by students with autism spectrum disorder (30\%). Participants were also given the opportunity to choose the option "Other Group", but were kindly asked to name that group. Four participants in total replied with this option, and gave us the following answers:

- Students with limited sight or hearing,

- Students with dysgraphia or other specific learning disabilities (SLD),

- Students with attention deficit hyperactivity disorder (ADHD),

- All students.

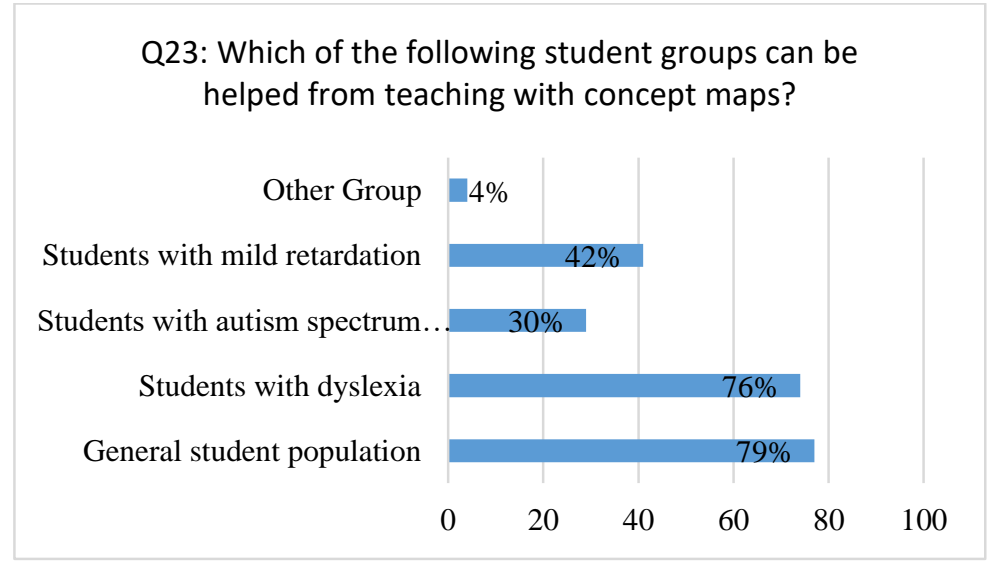

Figure 29. Group of students that could benefit from teaching with concept maps

In the last question (Question 24 - Figure 30) we asked the participants to help us optimize our effort. In total, 16 thought that they would be improved. In case their reply was "Yes", we kindly asked them to give us their suggestions. Unfortunately, not all 16 participants that replied "Yes" gave us their valuable feedback. Two educators suggested the use of more questions, five of them thought that the use of images could prove quite useful, and three suggested the use of more evaluation sheets containing concept maps.

Regarding their remarks, the use of more questions on the evaluation sheets could prove time consuming. Our goal for them is to be completed in 10 to 15 minutes maximum. The use of images could improve evaluation sheets, although the main scope of our study is on using concept maps. Finally, we are currently working on more evaluation sheets in science classes. 
Nevertheless, we did not want to provide participants excessive information that would require extra time. We believed this could discourage them from completing our questionnaire.

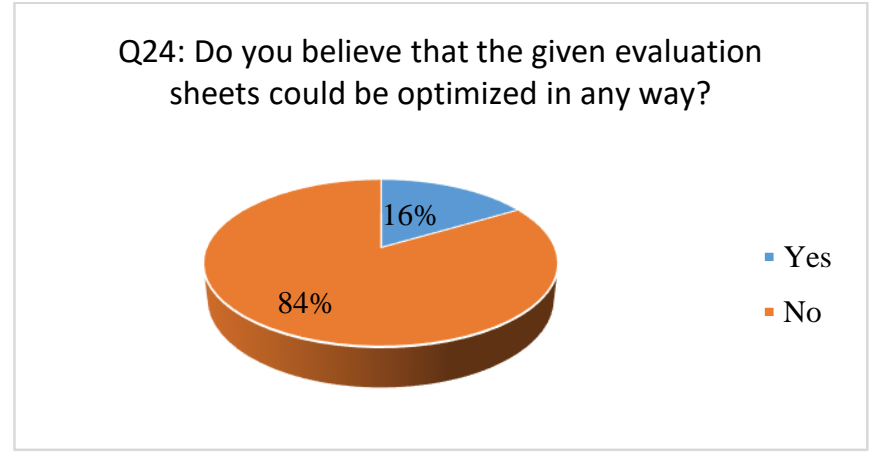

Figure 30. Participants reply on whether the evaluation sheets could be improved in any way

\section{Conclusions}

In this paper, we provided educators with four evaluation sheets and a questionnaire which are presented in the end of this paper. The participants that answered the questionnaire are quite young of age and with high education. So, they are quite established professionals that are highly skilled and well aware of the characteristics and challenges that apply to dyslexic students. More specifically, the majority of them use quite often evaluation sheets and have a quite good knowledge of concept maps.

Regarding our evaluation sheets, almost $60 \%$ believe they are very easy to understand, while $89 \%$ believe that they are at least quite easy to understand. Almost $80 \%$ of the participants answered that concept maps or evaluation sheets based on them can be quite helpful in recapitulation and revision of a science related topic. Moreover, $84 \%$ of the participants think that teaching that uses concept maps is more pleasant than any other conventional method.

In the questions referring to dyslexic students, participants thought that concept maps improve memory, metacognitive skills and facilitate learning of difficult and complex procedures.

The above is very encouraging, especially when it comes from such a knowledgeable group of colleagues. We firmly believe that concept maps can be a powerful tool to the science teacher to use them to general student population, as well as dyslexic student population.

Our future work includes the creation of even more evaluation sheets of the proposed kind and their application to students of the general population, but mainly to dyslexic students.

\section{Funding}

This research did not receive any specific grant from funding agencies in the public, commercial or not-for-profit sectors.

Conflicts of interest

None. 


\section{References}

Canas, A. J., \& Novak, J. D. (2017). What is a concept map? Accessed 9 December 2017, from https://cmap.ihmc.us/docs/conceptmap.php

Definition of dyslexia (2017). Retrieved 10 November 2017, from https://dyslexiaida.org/definition-ofdyslexia/.

Ferentinou, A., Papalexopoulos, P., \& Vavougios, D. (2009). Instructional adaptations in Physics for students with learning disabilities: The use of cognitive maps. $6^{\text {th }}$ Panhellenic Conference on Science Education and ICT in Education, 7-10 May 2009 (pp. 903-910). Florina: ISSN 17911281 Online Volume 6.

Lami, G. (2008). Dyslexia and concept maps: An indispensable tool for learning. In: A. J. Canas, P. Reiska, M. K. Ahlberg, \& J. D. Novak (Eds.), $3^{\text {rd }}$ International Conference on Concept Mapping "Concept Mapping - Connecting Educators", 22-25 September 2008 (pp. 152-154). Tallinn: OU Vali Press.

Pavey, B., Meehan, M., \& Davis, S. (2013). The dyslexia - Friendly teacher's toolkit: Strategies for teaching students 3-18 (71-73). London: Sage Publications Ltd.

Vlachos, A., \& Zamfirov, M. (2017). Concept maps: A tool for teaching dyslexic students Science. $4^{\circ} \Sigma v v \varepsilon \dot{\delta} \rho \iota$

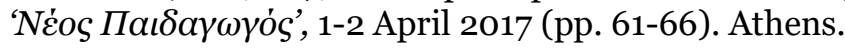

Zamfirov, M. (2011). Application of Lindsay, Rumelhart and Norman model in man and nature school subject with children with special needs. Dissemination and Development of Physics and Mathematics on the Balkans, 17-18 October 2011 (pp. 185-190). Sofia: Institute of Solid State Physics.

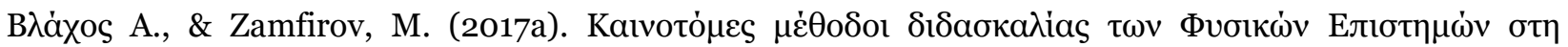

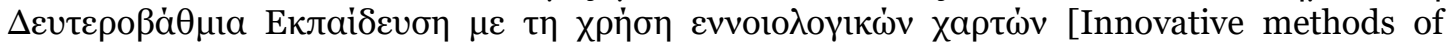

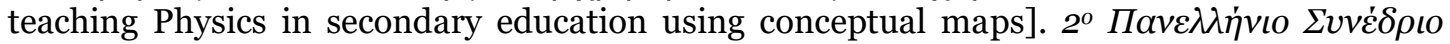

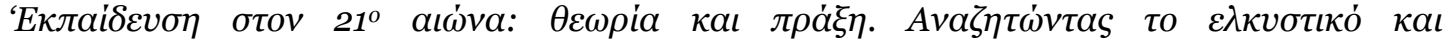

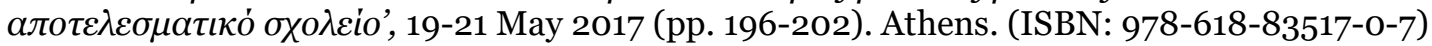

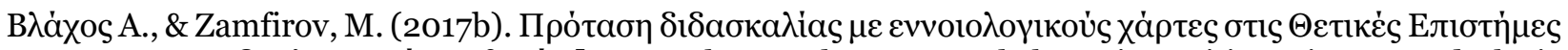
$\sigma \varepsilon \delta v \sigma \lambda \varepsilon \kappa \tau ו \kappa o v ่ s ~ \mu a \theta \eta \tau \dot{\varepsilon} \varsigma$ [Proposal to teach conceptual charts in positive sciences to dyslexic

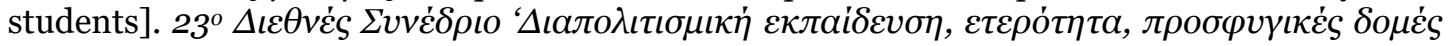

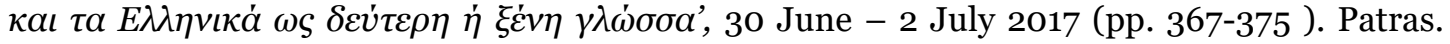
(ISBN: 978-618-82477-7-2)

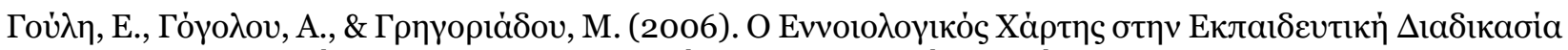

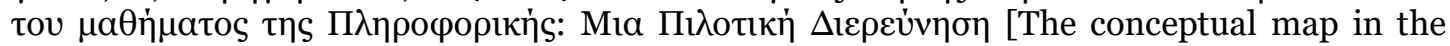

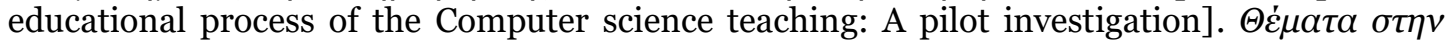

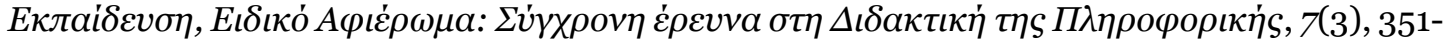
377.

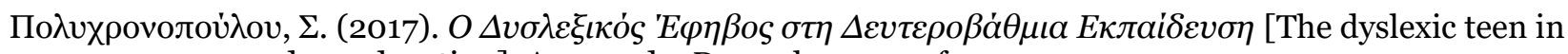
secondary education]. Accessed 9 December 2017, from https://www.specialeducation.gr/frontend/article.php?aid=335\&cid=75 
A. Vlachos \& M. Zamfirov - Using Concept Maps to Teach Dyslexic Students Science: ...

C O A $\mathbf{s}$ 